\title{
"Um raio em céu azul". Reflexões sobre a política de cotas e a identidade nacional brasileira
}

Amauri Mendes Pereira

\section{Resumo}

O texto aborda o pensamento social brasileiro com o propósito de contribuir para a elucidação do "choque social" provocado pelas propostas governamentais de cotas e ações afirmativas. Argumenta que a razão fundamental de tais propostas impactarem a opinião pública e terem sido vistas como um absurdo, um "raio em céu azul", é o fato da questão racial no Brasil vir sendo relegada a segundo plano no âmbito acadêmico do pensamento social - com a intelectualidade, em geral, patinando no senso comum - gerando desinformação e precária reflexão a respeito das desigualdades raciais. Como tem sido sempre intensa, rica e controvertida a interação de setores acadêmicos com a luta anti-racista, discute-se, então, sobre responsabilidades no quadro atual, em que o nível do debate social em torno das cotas e medidas de ação afirmativa é sintoma e resultado de escolhas investigativas, omissões e distorções na trajetória de instituição das Ciências Sociais no Brasil.

Palavras-chave: pensamento social brasileiro, negros, cotas, ação afirmativa, desigualdades sociais.

\section{Abstract}

"A lightning in blue sky". Reflections about quota politics and the Brazilian national identity

The text talks about the Brazilian social thought in an attempt to find out the "social clash" provoked by affirmative action propositions (quotas) made by the government. It shows that the main reason why 
these propositions have shocked the public opinion and have sounded like absurd, a lightning in blue sky, comes from the fact that in Brazil the racial matter has been left behind by the social thought among the academic sphere - in general, having the intellectuals expressing common sense ideas. That has lead to badly-informed people and shallow reflections about racial inequalities. As there has always been an intense and controvert interaction between academics and the anti-racist fight, the present responsibilities are discussed, focusing on how the social debate about the quotas and the affirmative action measures are a result of research choices, omissions, and distortions on the way to the institutionalization of the Social Sciences.

Keywords: Brazilian social thought, Brazilian racial matter, quotas, affirmative action, racial inequalities, public policy.

\section{Résumé}

\section{"La foudre dans le ciel bleu". Réfléxions sur la politique de cotes et l'identité national brésilienne}

Le texte aborde la pensée sociale brésilienne avec l'intention de contribuer à l'élucidation du "choc social" provoqué par les propositions gouvernementales de cotes et actions affirmatives. On défend l'idée que la raison fondementale de telles propositions qui causent un impact sur l'opinion publique et sont vues comme une absurdité, "la foudre dans le ciel bleu", est le fait que la question raciale au Brésil soit réleguée au second plan dans le contexte académique de la pensée sociale - avec les intelectuels qui patinent au sens propre du terme - et cela entraîne de la désinformation et une réflexion précaire quant aux inégalités raciales. Comme elle a toujours été intense, riche et controversée, l'interaction de secteurs académiques avec la lutte anti-raciste, on discute alors sur les responsabilités dans le cadre actuel, où le niveau du bébat social relatif aux cotes et mesures d'action affirmative est le symptôme et le résultat de choix d'investigations, d'omissions et de distortions dans la trajectoire de la mise en place des sciences sociales au Brésil.

Mots-clés: pensée sociale brésilienne, question sociale brésilienne, cotes, action affirmative, inégalités raciales, politiques publiques. 


\begin{abstract}
A questão das cotas para negros na Universidade caiu sobre a opinião pública brasileira como "um raio em céu azul". Esta célebre metáfora de Marx no Dezoito Brumário refere-se a um fato político absolutamente surpreendente (não para ele); tornou-se um alerta aos analistas, de que é necessário iluminar o fundo dos processos políticos, sociais e culturais, onde germinam os elementos que surpreenderão os incautos.
\end{abstract}

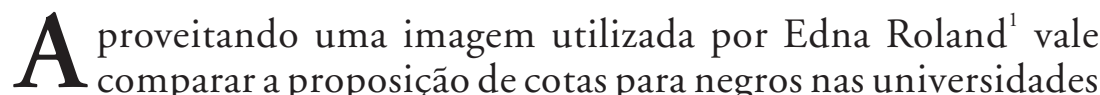
brasileiras, como os aviōes que vieram derrubar as nossas torres gêmeas: a inquebrantável harmonia/acomodação da democracia racial no Brasil. Foi grande a surpresa quando o presidente da República tornou pública - em rede nacional, durante a Conferência Mundial Contra o Racismo, realizada em 2001 - sua decisão autorizando a delegação brasileira em Durban a defender a adoção de cotas para atenuar as desigualdades raciais. No mesmo dia, e ainda sob o impacto da medida, o Fantástico, programa das noites de domingo da Rede Globo, realizou uma enquete entre os expectadores e confirmou o susto: a maioria era contrária às cotas.

$\mathrm{O}$ impacto fez tremer um dos suportes da identidade nacional brasileira. Tanto mais, porque essa construção identitária vem ocorrendo em meio a tensôes de variado tipo e extensão, ao mesmo tempo de forma bem-sucedida, embora fragmentadamente. Pode-se dizer que a maioria quer um país sem problemas raciais: para uns, isto significa fazer "desaparecer" os negros, ou que eles "embranqueçam", ou sejam embranquecidos; para outros, o respeito à diferença de brancos, negros, indígenas, orientais; para outros, ainda, a mestiçagem é que redimiria a todos... Outras idealizaçôes se somarão e/ou se mesclarão a estas. É um processo que engendra suas próprias resoluções, efêmeras, seqüenciais, descontínuas. 
O objetivo deste texto é introduzir uma abordagem do momento atual, no qual a adoção de cotas e o choque social decorrente não seriam um absurdo, um "raio em céu azul", mas o resultado de um processo sociocultural que tem relegado a questão racial a segundo plano.

Para isto, vou discutir brevemente a trajetória do pensamento social brasileiro e, dentro dele, dos chamados Estudos Afro-Brasileiros - estudos de relações raciais e sobre as manifestações culturais de matrizes africanas - e interrogar sobre suas responsabilidades no quadro atual, em que o combate às desigualdades raciais (via cotas e medidas de ação afirmativa), parece ser sintoma e resultado, já que tem sido sempre intensa, rica e controvertida a interação daqueles estudos com a luta anti-racista. O que teriam as Ciências Sociais a dizer neste momento?

É da percepção de que mesmo os pesquisadores dessa temática têm encontrado dificuldade para se posicionar que está nascendo este texto.

\section{Relações raciais - fator de tensão social}

Orientado por uma concepção nominalista de ciência, tenho defendido a existência de um desenvolvimento das relações raciais no Brasil que ainda não se deixou apreender nos conceitos e teorizações a seu respeito.

Penso que os estudos de relaçóes raciais dialogam muito mais entre si do que com a dinâmica efetividade (presença permanente, queira-se ou não) da questão racial no processo social brasileiro. Tal efetividade pode ser concebida como uma onipresença cuja explicitação, por meio de discurso/ação racista ou anti-racista, agride, perturba, rompe hábitos e conveniências, até tornar-se intolerável. Uma vez instalada, no entanto, exige solução, alguém tem de ceder - talvez por aí se possa pensar numa originalidade brasileira. Tal efetividade lembra $o$ frio da novela de Osvaldo de Camargo (1980), um mal oculto que ataca e contamina sub-repticiamente, com sintomas nem sempre diagnosticáveis, contra o qual se é normalmente impotente. Deve-se driblá-lo a todo momento, amealhando energias para (quem sabe, um dia!) enfrentá-lo.

Há pelo menos uma tentativa de captar a força daquela efetividade mediante análise sociológica. É, ao meu ver, o que faz Amauri de Souza ao identificá-la como um elemento importante na 
“Um raio em céu azul". Reflexões sobre a política de cotas e a identidade...

sustentação do projeto político de Getulio Vargas. Segundo este autor, "os negros e mulatos eram, na realidade a componente principal do povo que Vargas transformou, de cidadãos de segunda classe em um dos principais suportes do Estado Novo" (1971:64). Pouco importa para a análise deste autor a inexistência de referência à raça ou termo correlato nas ações de governo que ele vê como causa da "mobilização dessa população para formar a base política do Estado Novo e depois do PTB”. Ele avalia ainda que:

Até a implantação da legislação trabalhista, a discriminação ocupacional em virtude de fatores raciais era fato notório: não apenas era o negro, em sua grande maioria, confinado às posiçôes ocupacionais mais baixas e menos estáveis mas, mesmo quando aí empregados, ele era sub-remunerado [...]. Não foi necessário que o apelo de Vargas se dirigisse para minorias raciais. (idem)

Interessante nessa análise é que, embora o autor não refira, o "escurecimento" do mercado de trabalho foi determinado pela chamada Lei dos $2 / 3$ (em cada três trabalhadores, dois passaram a ser obrigatoriamente nacionais), uma lei que atendeu reclamos nacionalistas e proibiu a imigração de $3^{a}$ classe, quer dizer, de europeus pobres, já que intensa e eficaz campanha parlamentar procurava impedir a imigração regular de africanos e asiáticos. Também no texto dessa lei não há referência a raça.

Serve, também, como exemplo e sintoma da efetividade da questão racial a situação que tornou possível o primeiro general negro na história do Brasil, nos anos 60 . Consta que, independente dos méritos pessoais (confirmados ao longo de brilhante carreira), o Coronel João Batista de Mattos teria o mesmo destino de outros negros talentosos (dentro e fora das Forças Armadas) não fosse a proposição de seu nome para o generalato, em reunião do Estado Maior das Forças Armadas, por um General, com cuja família teria vínculos no passado. A proposição rompeu acordo tácito ao indicar um negro, provavelmente sem tocar na raça; mas já que foi feita, naquele contexto, não se deveria desqualificá-la com o argumento da raça - aí seria intolerável... E, afinal, um negro general (outro, só mais de vinte anos depois) representaria um bom escape!

Seria, também, uma boa explicação para a trajetória do TEN - Teatro Experimental do Negro, criado em 1945, e que atuou intermitentemente até o início da década de 60. Abdias Nascimento e seus companheiros e companheiras, usaram e abusaram da efetividade da questão racial, pressionando pessoas e instituiçóes para cessão de espaço nos quais realizavam seus espetáculos, como por 
diversas vezes fizeram no Theatro Municipal do Rio de Janeiro. Frente à sua obstinação, aliada à qualidade artística que projetou escritores, roteiristas, músicos, atores, atrizes, bailarinos etc., ${ }^{2}$ alguns membros da intelectualidade, ou detentores de cargos públicos, ou personalidades influentes, fossem eles mais ou menos solidários e anti-racistas, em algum momento teriam de ceder. Houve mesmo quem aproveitasse a oportunidade do enfrentamento imposta pela radicalidade da militância negra para aprender a solidariedade e o anti-racismo. ${ }^{3}$

Por último, um exemplo mais recente. Em 1988, toda a mídia veiculou campanhas tocando francamente na questão racial, embora por meio de símbolos tradicionalmente aceitos em mensagens sobre o negro (correntes, mãos brancas e negras entrelaçadas, negros-velhos de carapinha branca etc), com regularidade nunca vista. Ora, pressão para isso sempre houve por parte do Movimento Negro, e o fato de essas pressões adquirirem maior força naquele período não explica, sozinho, a mudança, mesmo porque a Rede Globo começou sua campanha ainda no mês de janeiro, longe, portanto, da intensificação das pressões. A minha hipótese é de que a efetividade da questão racial, dada a sua onipotência, opera uma sintonia entre a grande maioria da população (talvez especialmente a negra) e poderes constituídos - seja num, ou noutro contexto, procura-se evitar, pelo menos em público, procedimentos ostensivos em relação a fatos e idéias que toquem na raça; mas, uma vez instalado algum problema, deve-se encontrar solução satisfatória. Em geral, segue-se a linha do politicamente correto com a reafirmação da crença, ou da vontade/exigência da igualdade racial.

A escravidão é um dos poucos referenciais históricos que atravessa - como uma ferida de débil cicatrização - o imaginário social do brasileiro de todas as raças, classes, gêneros, idades e regiōes (embora, é claro, diferenciadamente). A expectativa que se anunciava no início de 1988 em torno da questão racial pode ser avaliada pela quantidade de piadas racistas que corriam "a boca pequena”, até mesmo entre negros, e por discussões cada vez mais candentes. ${ }^{4}$ As ansiedades geradas e a força que emanava daquele momento - o centenário da Abolição da escravidão, com seus apelos de crueldades, dores, sofrimentos, rancores, remorsos, ainda não devidamente purgados - empurrou os mais diferentes setores da sociedade a assumirem comportamentos de explicitação (os mais diferenciados, pode-se imaginar) até como procedimento catártico, em quase todos os setores da sociedade brasileira.' 
“Um raio em céu azul". Reflexões sobre a política de cotas e a identidade...

\section{O pensamento social é racial}

A efetividade da questão racial desenvolveu-se, apesar de contextos extremamente desfavoráveis, em que as elites intelectuais se esmeraram nas teorizaçôes e projeçōes a respeito do "problema negro". Da virada do século XIX para o XX, até os meados deste, talvez não se encontre intelectual brasileiro isento de racialismo, isto é, tendo a raça como centro do seu pensamento sobre a sociedade - até porque, para as elites, se apresentava como um dilema a construção de uma nação composta majoritariamente de descendentes de africanos. A instituição do Estado Nacional Republicano é simultânea ao incremento da imigração européia incentivada e subsidiada, um sintoma da vontade, das características da identificação das elites, e do esforço de se consolidarem perfis institucionais e ideológicos assemelhados aos modelos europeus à disposição. A pregação da necessidade de eugenia (pseudociência do aprimoramento racial) era um tema recorrente, então tratado com desembaraço. A influência dos teóricos do racismo científico alcançava em cheio as elites intelectuais brasileiras, embora Renato Ortiz (1986) tenha sublinhado a "criatividade" dos autores nacionais que selecionavam o que lhes interessava das doutrinas racistas vigentes.

Numa rápida digressão caracterizando as abordagens de uns e outros, e ilustrando a afirmação de que o pensamento social é racial, pode-se falar da obra teórica e metodologicamente repleta de equívocos e inconsistência de Nina Rodrigues, médico-legista baiano, de duradoura influência e eivada de um racismo profundamente pessimista, a ponto de Guerreiro Ramos (1957:145), aconselhar: "no campo das ciências sociais a melhor homenagem que se pode prestar ao cidadão comum Nina Rodrigues é fazer silêncio a respeito de sua obra"; ou da performance de João Batista de Lacerda, representante brasileiro no Congresso Mundial das Raças, em Londres (1911), assegurando aos seus descrentes pares que a mestiçagem (contrariando Gobineau - um dos principais teóricos do racismo científico - que a via como degenerativa), no Brasil era solução. Para o então diretor do Museu Nacional, aqui estaria se procedendo a uma redução étnica, com a eliminação gradual da população negra pela superioridade do sangue branco. Ou referindo o racismo otimista de Oliveira Vianna, personalidade fundamental nos primórdios da Sociologia entre nós, que advogava o incremento da imigração de dolicocéfalos-louros para higienizar, com seu genesuperior, o sangue do povo brasileiro - antes mesmo dos resul- 
tados do censo de 1920 aquele autor já sabia que a "evolução do povo brasileiro" (esse é o título do seu livro publicado como introdução àqueles resultados) se processava no sentido, irreversível, da arianização. Ou, lembrando, ainda, do I Congresso Brasileiro de Eugenia, em 1929, e a participação da nata das Ciências e das Letras nacionais, com suas teses para a higienização do povo brasileiro, sob a presidência de Edgar Roquette-Pinto (um pioneiro da implantação do rádio como veículo de difusão nacional) e relatório de Ignácio do Azevedo Amaral (um ícone da Educação no Brasil), de onde se extrai aconselhamentos do tipo:

o Primeiro Congresso Brasileiro de Eugenia dirigirá ao Presidente da República, às casas do Congresso Nacional e aos Governadores dos Estados, um apello em que serão postos em foco os gravíssimos perigos da imigração promíscua, sob o ponto de vista dos interesses da raça e da segurança política e social da República.

Ou, ainda, falando de Manuel Bonfim, um exemplo raro de intelectual brasileiro que já em 1905 superava o biologismo, pois mesmo ele, que desmascarava o darwinismo social tão presente entre nossas elites utilizando argumentos fornecidos pelo próprio Darwin, não consegue refutar inteiramente o ideal de branqueamento:

Indígenas e negros, sendo povos ainda muito atrazados, não possuiam nem qualidades, nem defeitos nem virtudes, que se impusessem aos outros e provocassem a imitação. Eram eles que, nesse encontro e entrecruzamento de raças, sofriam a influência dos mais cultos e os imitavam. (Bonfim, 1993.236)

Não se trata, aqui, no entanto, de nos estendermos sobre aquele pensamento, que certamente não é homogêneo e sobre o qual existe farta bibliografia (Seyfert, 1997), mas de observar a sua convergência no que toca à questão racial. Houve unanimidade entre a intelectualidade quanto à importância da imigração européia, sendo inexpressiva qualquer posição contrária ou que, de alguma forma, olhasse a situação "dos pobres negros, despossuidos e abandonados à sua própria sorte" . ${ }^{6}$ Não é preciso o domínio da bibliografia acadêmica sobre a situação da população negra nas primeiras décadas pós-Abolição para se falar do sentimento de abandono, generalizado nos meios negros das grandes cidades à época. O mesmo em relação a qualquer projeto de lei vislumbrando algum tipo de reparação aos ex-escravos. Nas áreas urbanas, para onde esses afluíam em grandes levas, ${ }^{8}$ formando as primeiras aglo- 
merações nas grandes cidades, e nas formas de colonato ou parcerias de variado tipo nas zonas rurais do Sudeste e do Sul, a exclusividade na alocação era para os imigrantes. A perspectiva dominante entre as elites era a substituição da população, pela imigração e pela mestiçagem a mais longo prazo. Ainda em 1964, Manuel Diégues Jr. vai insistir na importância da imigração e sua ênfase é sobre a necessidade de diversificar essa imigração, cujo "peso" de portugueses seria excessivo - mas sempre europeus. É sugestiva a forma como ele inicia o capítulo "O imigrante e o nacional" afirmando que: "A estrutura cultural luso-brasileira [...] baseada nos elementos originários portugueses, foi salpicada pelos valores negro-africanos e indigenas" (Diégues Jr., 1964:342).

A trajetória do pensamento social brasileiro tem sido de permanente recomposição, dando sempre a impressão de propriedade, de cabal interpretação e controle da evolução da questão racial na sociedade. Ao que parece, essa confiança entrou em crise com o anúncio das cotas, e com os debates mais amplos em torno das medidas de ação afirmativa, de reparações. É possível observar que a grande maioria da intelectualidade não toma posição a respeito. Um ou outro se arrisca eventualmente, mas quase sempre tangenciando a questão; apoio ostensivo, nenhum; contrários frontalmente, só exceções, nunca os mais renomados.

O pensamento social brasileiro, abusando da margem de manobra concedida pela ampla hegemonia cultural e pelos mecanismos institucionais e políticos de produção de conhecimento, declinou do seu papel de encaminhar uma ampla discussão nacional sobre o racismo, porque pensou poder postergá-la indefinidamente, e indefinidamente manter a paz social apesar das flagrantes desigualdades: um crime, no mínimo, de displicência, omissão, se não de cumplicidade com a perpetuação das desigualdades raciais e as defasagens simbólicas que compõem o escopo do racismo. E hoje depara com a "volta do ponteiro" - um momento de inevitável enfrentamento da efetividade da questão racial.

\section{Os estudos de relações raciais - um vírus inoculado}

A emergência dos chamados estudos de relações raciais dentro do campo dos estudos afro-brasileiros, a partir da década de 30, permitiu algo como uma desintoxicação do pensamento social brasileiro. Essa área espinhosa, porque muito exposta às tensões inerentes à crucialidade do tema, foi sendo relegada a segundo pla- 
no, tornando-se uma especialização - seus adeptos reclamam de uma certa marginalização no âmbito das Ciências Sociais - e serviu para resguardar o universo mais amplo da intelectualidade dos embates "comezinhos" gerados pela efetividade da questão racial.

Mas “quem dá o pão, dá o ensino”. Embora não possa ser vista linearmente - em quase 70 anos, foram muitas e significativas as descontinuidades e interseções teóricas, políticas, sociais -, será possível descartar qualquer ligação entre as cotas e medidas de ação afirmativa, hoje, e o papel fulcral da Fundação Rockfeller, e de outras norte-americanas, articuladas ao poder acadêmico no Brasil, na aurora dos estudos afro-brasileiros, financiando a vinda de pesquisadores norte-americanos, cujas marcas são tão visíveis? (Marinho, 2002).

Não devo enveredar por uma discussão mais complexa, sobre a sujeição, ou não, dos cientistas sociais brasileiros nessas áreas de estudos, aos ditames "imperialistas" da Sociologia norte-americana, conforme Bourdieu e Wacquant (1998). Estou sugerindo que os estudos afro-brasileiros, e dentro deles os estudos de relaçôes raciais - nem sempre prestigiados pelas áreas mais nobres das Ciências Sociais - tiveram liberdade para instituir seus próprios cânones teóricos, naturalmente com a complacência (e porque também atendiam conveniências) dos poderes acadêmicos. O que pretendo enfatizar é que quaisquer que fossem as influências teóricas e metodológicas, elas encontravam um meio acadêmico e um ambiente social propícios: o primeiro pela sua incipiência e carência de recursos, além do desinteresse/demissão da intelectualidade, da sua presunção de universalidade - o seu pensamento expressaria a totalidade, incapaz de questionar o "lugar social" de onde fala; o segundo, porque refletia aquele desinteresse, que tem o álibi de um período de sucessivas crises políticas e institucionais - os meados do séc. XX - em que o apelo à unidade nacional sobrepujava tudo, inclusive a necessidade de desvendamento da questão racial, em função da afirmação do país num mundo competitivo em aceleradas transformaçôes.

O resultado foi, então, a perda do controle. Um "descolamento" teórico e político de alguns estudiosos que, na busca de novas possibilidades explicativas, foram atraídos pela comparação com o que havia de mais visível: o contexto norte-americano. E se afastaram, então, do clima e da malha de interesses políticos e acadêmicos que acumpliciavam os estudos afro-brasileiros, o âmbito mais extenso das Ciências Sociais, e os setores políticos e instituci- 
onais "formadores de opinião" - mídia, Educação, religiōes, e personalidades influentes.

Sociólogos como Alberto Guerreiro Ramos e Luiz Aguiar da Costa Pinto, teoricamente tão diferenciados - além de inimigos pessoais - tiveram em comum a rejeição à "culturalização" do negro brasileiro (esta, sim, atravessando obras de quase todos os escritores nacionais), em detrimento da apreciação séria do problema racial. A insensibilidade da intelectualidade brasileira não conseguiu aproveitar a contribuição mesmo de Florestan Fernandes e de outros cientistas sociais influentes, que em trabalhos alentados alertaram para a importância de maior atenção à questão. $\mathrm{O}$ distanciamento olímpico da intelectualidade brasileira se manteve apesar da repercussão mundial dos embates travados no auge do Movimento pelos direitos civis dos negros norte-americanos. A partir daquele momento - anos 60 e 70 - talvez se possa falar de uma guinada para a "americanização" dos debates teóricos sobre o racismo e das lutas políticas contra o racismo, no Brasil, dos quais o Movimento Negro tem sido o motor e a ponta-de-lança. Uma nova geração de pesquisadores brancos e negros norte-americanos trouxe a público seus trabalhos. Thomas Skidmore (que viera ao Brasil para estudar a era Vargas e se sentira confrontado pelo escamoteamento da questão racial), e Carl Degler, lançam seus livros nos EUA (Skidmore, 1989; Degler, 1976), que logo adiante seriam traduzidos, com sucesso, para o português. E em 1979, é traduzida para o português a tese de Carlos Hasenbalg, defendida nos EUA, que veio a se tornar um marco na literatura de relações raciais no Brasil. Entre outras inovaçôes teóricas, questiona o cerne da concepção da chamada Escola Paulista (com Florestan Fernandes à frente) do racismo como um arcaísmo, um resquício da escravidão, apresentando a materialização da discriminação racial através de mecanismos institucionais e de estatísticas sobre as desigualdades raciais.

\section{Pós-Durban}

Não surpreende que Ricardo Henriques (2001) agradeça, na página de rosto do seu texto "Desigualdade racial no Brasil: evolução das condições de vida na década de 90”, a Carlos Hasenbalg, pelos comentários. Esse texto e seu autor tornaram-se referências obrigatórias na cruzada atual pelas medidas de ação afirmativa devido, principalmente, à potência de seus conteúdos estatístico e 
analítico sobre as desigualdades raciais, mas também pelo fato de representar a posição de um pesquisador "oficial", do IPEA Instituto de Pesquisas Econômicas Aplicadas, do Ministério do Planejamento. Vejo-os como a culminância de duas décadas de produtividade intensa e articulada das pesquisas com esse viés no Brasil, em que se destaca Hasenbalg, a partir do êxito em articulações e da produção acadêmica do Centro de Estudos Afro-Asiáticos-UCAM, que ele dirigiu de 1982 a 1997. É de se observar o nível de engajamento pessoal e teórico de pesquisadores influentes junto aos centros de poder - Ricardo Henriques e o então presidente do IPEA, Roberto Martins, são dois deles - empenhados na ampliação da discussão especificamente focada nas desigualdades raciais. E mais ainda, a sua mais que perfeita interação com o que podemos designar provisória e cautelosamente de setores de ponta do Movimento Negro. Além de subsidiar projetos e ações estratégicas das ONGs e de personalidades negras vis-à-vis agências fomentadoras de variado perfil, eles se dispuseram, em dado momento, a intermediar a incorporação de pesquisadores negros e de seus projetos de pesquisa à agenda de órgãos oficiais de apoio à pesquisa, e até mesmo no interior do próprio IPEA.

A argumentação que venho esboçando neste tópico pretendeu resumir (muito rapidamente) a formulação provisória de como o pensamento social brasileiro se omitiu de discutir a questão racial e "segregou" os estudos afro-brasileiros; de como, nesse âmbito, vão conquistando proeminência os estudos de relações raciais; e o crescente "descolamento"/autonomização, de um determinado viés desses últimos: o foco nas estatísticas e análise das desigualdades raciais. E que isso representaria a "perda de controle" por parte das elites intelectuais, desinteressadas da publicização, intensificação, aprofundamento, desses temas.

Ao longo do processo preparatório da Conferência Mundial Contra o Racismo (2000/2001) foi se formando um leque de alianças entre militantes do Movimento Negro e de outros Movimentos Sociais (quase sempre negros), setores acadêmicos, uns poucos setores de mídia, setores governamentais e também do Legislativo e Judiciário, que tem dado mais e mais visibilidade à questão das desigualdades raciais e à necessidade de implementação de ações afirmativas. Esse contexto de alianças vem se consolidando e tem sido amplamente vitorioso na hegemonização do discurso e ações anti-racistas no Brasil. Isso ficou explícito na atuação complementar (embora permeada por tensóes) das delegações oficial e de ONGs negras no processo de mobilização, no Brasil, e nas ins- 
tâncias oficiais da Conferência Mundial Contra o Racismo. E aquelas alianças se confirmaram no pós-Durban, municiando discursos e medidas governamentais no que toca ao enfrentamento das desigualdades raciais, e também junto aos poderes Legislativo e Judiciário e a alguns setores da sociedade civil. Uma característica central desse contexto de alianças, todavia, é que ele tem tratado exclusivamente da materialidade do racismo (enfoque precioso, por sinal, em terras de "racismo camuflado"), mas que relega suas dimensões históricas, simbólicas, a segundo plano.

Cabe, agora, refletir sobre a complexidade desse processo social e político e indagar da pertinência ou não das conjecturas que venho desenvolvendo: se, realmente, a intelectualidade brasileira - os "formadores de opinião" via mídia, debates políticos e acadêmicos etc. - perdeu o controle, seja da discussão teórica, seja dos encaminhamentos práticos/estratégicos de enfrentamento das desigualdades raciais, enquanto, à sua revelia, podem se desenvolver antagonismos de mais difícil equacionamento.

Em caso negativo, deveremos buscar outros caminhos para a compreensão do porquê da surpresa e comoção nacional frente às propostas de cotas e ações afirmativas. Ainda mais se lembrarmos que Fernando Henrique Cardoso, o presidente da república, como sociólogo, se especializou nessa área de estudos e, ao longo do seu governo, tocou várias vezes no assunto e assumiu oficialmente, em foros internacionais, a existência do racismo, além de apoiar militantes negros com quem privara de certa proximidade política e de prestigiar a liderança da Marcha de Zumbi dos Palmares, de 1995, criando, a seguir, um Grupo de Trabalho Interministerial de combate ao racismo. ${ }^{10} \mathrm{E}$ nada disso conseguiu despertar a letargia das elites intelectuais sobre o problema.

Se, afirmativamente, é imperativo avaliar responsabilidades. Por enquanto tem sido difícil, às vezes ríspido, o diálogo entre os pró e o contra as açôes afirmativas. A bem da verdade, os primeiros têm sido propositivos, articulados e eficazes, conclamando ao debate e esgrimindo estatísticas e argumentações substanciais. Seus discursos têm falado na emergência e transitoriedade das cotas e ações afirmativas e na necessidade do enfrentamento da questão racial em todos os setores da sociedade. Os segundos têm sido mais reativos e reiteram, em geral, a postura universalista que sempre caracterizou o senso comum em torno da mestiçagem e da vocação brasileira para a harmonia racial, da importação desse problema etc. Contrapóem-se a medidas preferenciais para negros em setores dos serviços públicos, para apresentações na mídia etc., se bem 
que não respondem aos reclamos de que esses são tradicional e ostensivamente brancos. Reafirmam a exigência do mérito (que se manifestariam nas melhores notas nos vestibulares) como único critério para galgarem vagas nas universidades públicas, e alertam para a racialização intrínseca aos procedimentos que estão sendo adotados. A quem interessa a cristalização dessas posiçôes?

Um dado adicional é a surpreendente contrariedade de estudiosos da questão racial, como o professor Peter Fry, por exemplo, com o desaguar desse processo. ${ }^{11}$ Ele é favorável às medidas de ação afirmativa, mas contrário às cotas, que vê como fator socialmente diruptivo, ao enfatizar as diferenças raciais e levar ao caminho da intolerância. Esse influente estudioso das relações raciais, inglês de nascimento, naturalizado brasileiro, foi responsável, inclusive, pelo apoio maciço e decisivo à linha de pesquisas desenvolvida por Hasenbalg e outros, no início dos 80 , quando dirigente da Fundação Ford - uma das agências de fomento mais atuantes no que toca à questão racial, no Brasil - onde seu pensamento sempre gozou de respeitabilidade.

O que terá acontecido? Estaria a ação problematizadora das desigualdades raciais, radicalizada na prescrição de cotas, em descompasso com a "tradição" de cautelosa e resguardada interação do campo científico com a efetividade da questão racial ${ }^{12}$ Teria havido uma ruptura política e estratégica de alguns agentes (acadêmicos/políticos) a partir do êxito da linha de estudos que enfatiza as desigualdades raciais? (Como exemplos: já em 1999, em seu livro Racismo e anti-racismo no Brasil, o professor Antônio Sérgio Guimarães, da USP, pôs um título provocativo no terceiro capítulo: "Tomando partido", com sólida argumentação a favor das medidas de ação afirmativa). Mesmo após a saída de Roberto Martins e de Ricardo Henriques do IPEA, continuam nesse órgão do Ministério do Planejamento as análises que ressaltam a importância do enfrentamento das desigualdades raciais. Estariam aquelas rupturas acadêmicas/políticas provocando ou, antes, expressando (ou ambas as coisas) rachaduras nas "torres gêmeas" da identidade nacional brasileira?

Muito se tem escrito, nas Ciências Sociais, a respeito de identidades. Sob a ótica das teorizações atualmente mais influentes a respeito, poderia soar quase como um anacronismo referir a efetiva construção da identidade nacional como uma solução na perspectiva complexa de interações raciais e étnicas dos brasileiros. Quem sabe?

Hall, mapeou 
“Um raio em céu azul”. Reflexões sobre a política de cotas e a identidade...

as mudanças conceituais através das quais, de acordo com alguns teóricos, o sujeito do Iluminismo, visto como tendo uma identidade fixa e estável, foi descentrado, resultando nas identidades abertas, contraditórias, inacabadas, fragmentadas do sujeito pós-moderno. (Hall, 2001:46)

Penso que algo semelhante se poderia propor para uma concepção de identidade nacional. Algo como o captado por Chatterjee (2000), analisando a luta anticolonial na Índia. Ele identificou um momento em que o nacionalismo rejeitou o direito do Estado colonial de intervir em aspectos essenciais da identidade cultural da nação. Era uma dimensão do nacionalismo que se instituía a partir de espaços resguardados de significações no seio da população. A construçãao desses espaços implicaria considerável energização dos esforços de afirmação étnica/racial em populações subordinadas. Poder-se-ia desconhecer/menosprezar esses acúmulos que teceram auras de heroísmo que recheiam a crônica das lutas anticoloniais e de conquistas libertárias de tantos povos?

Não há, nem linearidade, nem tanta distância conceitual, entre as lutas de libertação nacionais, no outrora chamado Terceiro Mundo, e as lutas da população negra na sociedade brasileira. Como desprezar aquelas referências frente à apropriação pela identidade nacional brasileira de tantos símbolos negros de origem, e ao mesmo tempo recusar a ultrapassar o meramente simbólico e enfrentar as demandas da população negra por igualdades de oportunidades em todas as instâncias da vida nacional?

Não vejo identidade nacional como uma simples transposição/coletivização de identidades particularizadas. Mas a discussão de Hall (1998) sobre a descentração do sujeito do iluminismo e sua reconstituição na "modernidade tardia", ajuda a pensar o esforço de homogeneização/assimilação que as elites pretendem impor à população negra brasileira. A crença nessa homogeneidade ontológica traz a perplexidade, quando o combate do Movimento Negro ao racismo, face à obstrução de outros caminhos, é levado à significação da diferença. Para Hall, os sujeitos sempre respondem a interesses. O contrário do que transparece na discussão psicológica/filosófica de Giddens (1991), na qual este induz a existência de um âmbito íntimo na constituição do ser, que não seria dado à reflexividade, à cognição, à consciência - o que ele designa conscientização prática. Se, por um lado, ele questiona as bases do racionalismo que fundamentam a civilização ocidental, por outro, deixa de perceber a heterogeneidade, a complexidade de interações presente na discussão de Hall. Este não teme, nem consagra a dife- 
rença; ela pode ser transitória no fluxo de identificações em sociedades complexas. Aquele deixa transparecer a sua vontade de que haja a homogeneização. Penso que há, entre os dois, uma diferença crucial de caráter político-ideológico que os distancia: a formação de ambos, o lugar "racial" de onde estão falando, uma bagagem construída socialmente, que os informa, por trás de suas posturas teóricas. Giddens (e outros teóricos, junto aos quais se sentiriam à vontade eminentes pensadores sociais brasileiros) ao falar de identidades, que elas são construídas, inventadas, está falando "dos outros". Ele não questiona o seu "lugar de enunciação" e o quanto esse "lugar" compromete o suposto universalismo de sua formulação.

Problematizando identidades africanas em contextos pós-coloniais, quando elas muitas vezes antagonizam processos de transformação nacional e tentam enfeixar diferentes perspectivas em camisas-de-força de tradições étnicas idealizadas, Appiah diz

sou aplicado o bastante para me sentir atraído pela enunciação da verdade, mesmo que o mundo venha abaixo; e sou animal político o bastante para reconhecer que há lugares em que a verdade prejudica mais do que ajuda. (Appiah, 1997:243)

Não me parece que ele esteja falando apenas de questão de ética, que procura não romper, buscando alternativas para esse enunciado. $\mathrm{O}$ que ele está afirmando é que a construção da solidariedade africana não pode passar pela afirmação da raça e das tradições nacionais, que seriam "falsidades inuteis, ou pior, perigosas: que um outro conjunto de história nos construirá identidades através das quais possamos fazer alianças mais produtivas" (ibidem). Aproveitando esta reflexão para o caso brasileiro, poderiam se questionar as bases do mito da democracia racial que apontam para um passado idealizado, fundamentando a construção de uma identidade nacional idealizada, no qual o elogio da mestiçagem serve como anteparo da hierarquia racial, e no qual a branquidade se encontra no topo; tudo isso exigindo da população negra que se renda a tais idealizações. Penso que tal exigência seria (tem sido) nociva, do ponto de vista de que a diversidade representa a maior fonte de riqueza na constituição de um povo. E paradoxal, porque postula que a população negra deveria renunciar ao combate às desigualdades, à demanda de plena integração social à nacionalidade brasileira; quando tal perspectiva, em se tornando realidade, redundaria em fortalecimento dessa mesma sociedade nacional. 
Considerando a consistência desses alertas é razoável propor que nem sempre são armadilhas as demandas de rompimento com identidades nacionais, instituídas sobre bases suspeitas da universalidade dos setores hegemônicos, e de construção de outras, que partam da heterogeneidade.

A idealização de um país sem problemas raciais é uma vontade forte (e bonita) demais para se descuidar dela. Ela vem se equilibrando entre a ilusão e o sonho da igualdade. A cristalização das desigualdades, de um lado, e a exacerbação das diferenças para combatê-las, por outro, podem fazer degenerar aquela condição tênue, paralisando/obstruindo o fluxo de identificações que (embora diferenciadas e até conflituosas), no caso brasileiro, vêm representando um alento, emoldurando as imagens distorcidas no espelho e (apesar de tudo!) criando suas próprias soluções parciais.

A despeito de uma hegemonia racial em todas as instâncias de poder, emergiu - a partir da profícua interação do Movimento Negro com a delegação oficial (agentes de governo e de Estado) ao longo do processo preparatório e durante a Conferência Mundial Contra o Racismo, em Durban, África do Sul, em 2001 - um contexto de alianças contra-hegemônico altamente eficaz no incremento das discussões sobre as desigualdades raciais. É tentadora a oportunidade de lembrar a famosa imagem usada por Marx, ainda no 18 Brumário, em relação a situações de fato: "Aqui é Rodes, salta aqui". Frente ao desafio do quadro atual, não resta ao pensamento social e ao universalismo que transborda para o senso comum configurando a identidade nacional brasileira, mais do que fazer acontecer a vocação de igualdade e harmonia que sempre proclamou. Começa por enfrentar a discussão, e isso pode e deve se dar acadêmica e politicamente em bases democráticas. Se a solução não passa pelas cotas, qual a proposta? A inércia e as digressões como a alegação de que em vez das cotas se deveria oferecer ensino público de qualidade a todos (como se isso fosse contraditório com a proposta emergencial das cotas) - não são mais cabíveis.

Preconizar a adoção de cotas fortalece a questão da raça - o que é um problema. Mas como um movimento tático, de caráter emergencial e temporário, cumpre o duplo papel de tensionar a sociedade em direção ao enfrentamento das desigualdades, e de expor a fragilidade, nesta questão, do pensamento social brasileiro, obrigando-o a se voltar sobre si mesmo, observando suas lacunas, com a oportunidade de engajar-se na efetiva construção do universalismo, em vez de esvaziá-lo em insensata proclamação idealista. A intelectualidade brasileira não quis e/ou não foi capaz de enfren- 
tar os preconceitos e a discriminação racial que grassavam à sua volta, nem sequer conter a dissensão teórica e metodológica gerada em suas entranhas pelos estudos de relações raciais.

Pensando ainda com Appiah, ele enfatiza a necessidade de os cientistas sociais continuarem dizendo suas verdades, mas que é importante incorporar

um intenso sentimento da marginalidade desse trabalho para a questão central da resistência ao racismo e à violência étnica [...] a verdadeira batalha não é travada nos círculos acadêmicos. (Appiah, 2001:248)

\section{Notas}

1. Militante negra brasileira que fez parte da delegação oficial ao longo do processo preparatório e na Conferência Mundial. Por sua destacada atuação, foi indicada pela representação brasileira e eleita a relatora oficial daquele evento.

2. Os nomes de Ruth de Souza, Léa Garcia, Mercedes Batista, Haroldo Costa, que consolidariam suas carreiras adiante, são emblemáticos. Abdias do Nascimento chegou a contracenar com Cacilda Becker.

3. O sociólogo negro Alberto Guerreiro Ramos confessa ter rejeitado, a princípio, o assédio de Abdias Nascimento, que considerou “um reivindicador contumaz". Aos poucos foi percebendo suas razões e assumindo posturas teóricas e engajamento político como negro.

4. Uma piada que chegou a causar muita confusão e incontáveis pequenos conflitos (muitos deles noticiados pela imprensa) era de que a Lei Áurea se esgotaria e se poderia voltar à escravidão. Um outro indicador do nível de tensão a que se poderia chegar foi a sucessão de artigos nos principais jornais, discutindo a oportunidade e as características do Programa Nacional do Centenário da Abolição, capitaneado pelo Ministro da Cultura, Celso Furtado (intelectual de renome), e instituído no dia 21 de março pelo presidente da República, José Sarney. O livro de Edson Lopes Cardoso, Bruxas, espiritos e outros bichos (1992), arrola e comenta notícias e artigos publicados naquele período. Ali se encontra parte da pesquisa que gerou a dissertação de mestrado em Comunicação defendida pelo autor na UnB, em 1990.

5. Uma incursão ao conteúdo dos jornais das grandes cidades entre março e maio de 1988, assim como um levantamento dos eventos realizados nas mais diversas instituições da sociedade civil e dos Movimentos Sociais, comprova o que foi observado empiricamente por quantos estivessem voltados a isso. Ainda a leitura dos jornais em todo o país, no dia 12 de maio, oferece um bom retrato do que foi o absolutamente desproporcional aparato de repressão que escandalizou a mídia nacional e internacional (não se vira tal quantidade de tropas desde 1968, nem nas campanhas pela Anistia, ou pelas Diretas), e que foi mobilizado pelo Comando Militar do Leste contra uma passeata mobilizada pelo Movimento Negro no dia anterior, no Rio de Janeiro. Não foram apenas a quantidade de militantes (estimada em cerca de quinze mil pela PM, cujos serviços de informação haviam previsto), nem o alegado ataque que se faria à estátua de Duque de Caxias, os fatos responsáveis pelo desatino dos militares. $\mathrm{O}$ 
relato de membros do Comando da Marcha (jornal Força Negra, novembro de 1988), de que, inclusive, o Secretário de Segurança do Estado do Rio de Janeiro Hélio Saboya - se confessara perplexo: "os militares estão loucos", permite se pensar que maior do que a força do Movimento Negro - que eles tinham como contabilizar e, se fosse o caso, controlar - era o temor da dimensão que poderia alcançar um evento daquele tipo, com tamanha carga emocional, capaz de potencializar a efetividade da questão racial, colocando aquele contexto à beira da ruptura, do enfrentamento desabrido dos militantes contra as forças policiais e militares.

6. Frase extraída do jornal Tribuna Negra, órgão da Imprensa Negra paulistana, 1935.

7. A frustração com o fato de a abolição da escravidão não ser seguida de outras medidas que atenuassem as desigualdades raciais e promovessem a efetiva integração do negro à sociedade, teria se tornado ressentimento contra a crueza das instituiçôes republicanas, gerando fenômenos como a guarda negra. Ver, a respeito, artigo de Carlos Eugênio Líbano Soares (1993).

8. José Correa Leite e Cuti. E disse o velho militante José Correia Leite. São Paulo, Secretaria Municipal de Cultura, 1992.

9. Tenho conhecimento direto de pelo menos uma organização negra com quem estiveram em estreito contato: o CEAP - Centro de Articulação de Populações Marginalizadas, que produziu um "Programa Nacional de Pesquisas e Análise de Políticas Públicas para os Afro-Brasileiros" como "proposta para o IPEA".

10. Em 1995 - ano do Tricentenário de Zumbi dos Palmares -, a sociedade brasileira assistiu a um incremento extraordinário de eventos capitaneados, em geral, por militantes do Movimento Negro. Uma das principais articulações de militantes realizou, em novembro, a "Marcha Zumbi dos Palmares Contra o Racismo, Pela Cidadania e a Vida”. Foi uma mobilização nacional que desaguou na Esplanada dos Ministérios, num grande comício com a participação de importantes lideranças políticas e artistas. Ao final, "Missa dos Quilombos", de Milton Nascimento, com orquestra e coral, em quase duas horas de espetáculo.

11. Entrevista de Peter Fry ao jornal Capital Cultural, Rio de Janeiro, junho de 2002.

12. Não pretendo, aqui, entrar no mérito da importância do MN para essa nova conjuntura da luta contra o racismo.

\section{Referências Bibliográficas:}

APPIAH, K. A. (1997). Na casa de meu pai. Rio de Janeiro, Ed. Contraponto. BHABHA, Homi (1998). O local da Cultura. Belo Horizonte, Ed. UFMG.

BONFIM, Manuel (1993). A América Latina-Males de Origem. Rio de Janeiro, Topbooks.

BOURDIEU, Pierre \& WACQUANT, Loïc (1998). Prefácio: sobre as artimanhas da razão imperialista. In P. Bordieu, Escritos de Educação. Petrópolis. Vozes.

CAMARGO, Osvaldo (1980). A descoberta do frio. São Paulo, Edições Populares.

CARDOSO, Edson Lopes (1992). Bruxas, espíritos e outros bichos. Belo Horizonte, Mazza Ediçóes.

CHATTERJEE, Partha (2000). Comunidade imaginada por quem? In G. Balakrishnan (org.), Um mapa da questão nacional. Rio de Janeiro, Contraponto. 


\section{Amauri Mendes Pereira}

DEGLER, Carl (1976). Nem preto nem branco. Rio de Janeiro, Editorial Labor do Brasil.

DIÉGUES JR., Manuel (1964). Imigração, urbanização e industrialização. Rio de Janeiro, CBPE/INEP.

GUERREIRO RAMOS, A. (1957). Introdução crítica à sociologia brasileira. Rio de Janeiro, Editorial Andes.

GIDDENS, Anthony (1991). Modernity and self identity. Oxford, Polity Press, caps. 2 e 3 .

HALL, Stuart (1998). A identidade cultural na pós-modernidade. São Paulo, DP\&A.

HASENBALG, Carlos A. (1979). Discriminação e desigualdades raciais no Brasil. Rio de Janeiro, Graal.

LEITE, José Correia \& Cuti (1992). Edisse o velho militante Jose Correia Leite. São Paulo, Secretaria Municipal de Cultura.

MARINHA, Maria Gabriela M. C. (2002). Norte-americanos no Brasil. Uma história da Fundação Rockefeller na Universidade de São Paulo (1934-1952). São Paulo, Edusp.

ORTIZ, Renato (1986). Cultura e identidade nacional. São Paulo, Brasiliense.

SEYFERT, Giralda (1997). A assimilação dos imigrantes como questão nacional. MANA, vol. $3, n^{\circ} 1$.

SKIDMORE, Thomas (1989). Preto no branco. (2a ed.). Rio de Janeiro, Paz e Terra.

SOARES, Carlos Eugênio Líbano (1993). "Na flor da gente à Guarda Negra: os capoeiras na política imperial”. Estudos Afro-Asiáticos, no 24 .

SOUZA, Amaury de (1971). "Raça e política no Brasil urbano". Revista de Administração de Empresas, out./dez. 